\title{
Chapter 15 \\ By Way of Summary: Substantive \\ Contributions and Public Policies \\ for Dealing with Social Inequalities
}

\author{
Sandra Fachelli and Pedro López-Roldán
}

\begin{abstract}
The final chapter aims to summarize the main substantive contributions of each of the preceding ones and the public policies that could be applied to deal with social inequalities. It also presents a general proposal for a future research programme in comparative analysis of social inequalities between Europe and Latin America.
\end{abstract}

\subsection{Substantive Contributions and Public Policies}

In this section a brief text summarizes the main contributions and conclusions of each chapter of the book. We have also included the result of a collective synthesis work carried out with the authors of the book, and in which we have tried to harmonize the different issues addressed in the book by presenting synthetically the theme that each chapter examines, the inequalities observed in each field, the policies that could be established to face such inequalities and the political-administrative bodies that would be in charge of implementing these policies.

\footnotetext{
S. Fachelli $(\bowtie)$

Departamento de Sociología, Universidad Pablo de Olavide, Sevilla, Spain

Grupo de Investigación en Educación y Trabajo, Universidad Autónoma de Barcelona,

Barcelona, Spain

e-mail: sfachelli@upo.es

P. López-Roldán

Centro de Estudios Sociológicos sobre la Vida Cotidiana y el Trabajo - Instituto de Estudios del Trabajo, Universidad Autónoma de Barcelona, Barcelona, Spain

e-mail: Pedro.Lopez.Roldan@uab.es
} 


\subsubsection{About Social Models}

In the introduction to this book, Chap. 1 presented the context of the INCASI project, aimed at creating and consolidating a network for the comparative analysis of social inequalities. It presented the general conceptualization of social inequalities and the Analytical Model of Social Inequalities and Trajectories (AMOSIT) that oriented the work of the network. From this general analysis model, the concept of a social model is highlighted as a global typological and structuring concept of multiple elements that characterize social inequalities in each European and Latin American country and the pre-distributive and post-distributive policies for dealing with them. This proposed classification formed the basis for the rest of the topics and studies covered in the book.

This conceptualization of social models identifies the institutional characteristics of labour market coordination that explain pre- and post-distribution inequality, providing a conceptual framework to facilitate the comparison of institutions and inequalities between the countries participating in the INCASI project. Relevant indicators are put in play to characterize four social models that correspond to four types of coordination of economies:

1. Uncoordinated informal economies, which have high levels of informality, intermediate levels of collective bargaining coverage, low social expenditure and low unemployment coverage. These include Argentina, Uruguay and Brazil. Corrective averages (post-distribution) are not very powerful and start from high levels of inequality.

2. Neo-corporatist coordinated economies, which have low rates of informality, the highest levels of collective bargaining and social spending coverage and the highest unemployment coverage. These include the countries of the Ghent System (Belgium, Sweden, Norway, Denmark and Finland) and the Germanic countries (Germany, Austria and the Netherlands). Corrective measures of inequality are observed in changes in the post-distribution Gini index, and these countries are the ones with the lowest inequality.

3. Uncoordinated economies, which are characterized by the decentralization of collective bargaining at company level and informal employment (widespread in Latin America). There is a sharply dualized segmentation of labour relations marking a clear difference between protected workers (insiders) and unprotected workers (outsiders), leading to low rates of unemployment protection, a medium level of informal employment and high levels of inequality. These include the United Kingdom, the United States and Chile. The corrective measures have effects but these are lower than in coordinated or semi-coordinated economies.

4. Semi-coordinated economies, which have collective bargaining systems that mix centralization at the sector level, semi-decentralization at the regional level and bargaining at the company level. In those countries, trade unions hold political influence and capacity for mobilization. These countries have a medium level of social expenditure, informal employment and unemployment protection. They include Spain, Italy, France, Greece, Portugal and Slovenia. Corrective measures manage to operate and reduce the post-distribution Gini but to a lesser extent than in coordinated economies. 
This analysis shows a transformation of the State in Europe that leads to a deterioration of the social protection system, a change that is characterized by a socialization of risk indicative of a shift from the benefactor-protector paradigm to the active social state paradigm. In short, Europe is slowly approaching Latin America and is not on the right track. Therefore, the recommendations for both continents are the same: (1) a high coverage rate of collective bargaining helps to reduce inequalities; (2) the employment rate alone does not reduce inequalities, since jobs can be unstable, temporary, part-time, informal and poorly paid; and (3) extreme measures should be applied to lower the high rate of informal employment because it affects both pre- and post-distributive policies.

The following table shows some proposals for public policies aimed at dealing with inequalities in this area:

\section{Phenomenon analysed}

Pre-distribution institutions and post-distribution institutions

Inequalities observed

Income inequalities: pre-distribution Gini index, post-distribution Gini index, occupational rate and informal employment.

\section{Most important policies for addressing these inequalities}

Re-orientation of state social policies to the benefactor-protector paradigm

Collective bargaining coverage

Expenditure on social policies

Unemployment protection rate

Important bodies for carrying them out

State institutions

Trade unions

Employers' associations

Institutional arrangements for social dialogue: an advisory board for industrial relations

Source: A. Martín-Artiles, E. Chávez-Molina and R. Semenza (Chap. 2)

\subsubsection{Labour and Educational Inequalities}

\subsubsection{Segmented Labour Markets}

Analysing social inequalities in the labour market from a comparative perspective, the first general conclusion is that the stratification of countries' labour markets is structured according to two main factors: socio-economic development and employability. Countries can therefore be clustered into four types: less development with more or less employability; and more development with more or less employability.

A comparative analysis of labour market segmentation, in particular between Spain and Argentina, shows a common general pattern of structuring of their labour markets that typifies employment into four segments. In this typification, the two countries show great similarity in the percentage distribution and, above all, in the dominant profiles. In both cases, moreover, there is a correspondence between the structure of the labour market and the characteristics of the supply and demand 
sides of the labour force. It is important to note that in both Spain and Argentina the types of segmentation are the relative expression of the labour realities specific to each region, so the grouping reflects characteristics with very similar features despite the different contexts of development and social regulation. The occupational and educational structure differ, and informality is a very distinctive phenomenon in Argentina, but despite these different socio-productive contexts, the structuring of inequalities in the labour market shows many common elements in the factors of differentiation and types of employment. This result raises the question of the extent to which other countries of the two continents confirm, qualify or contradict this common pattern of segmentation, which can be clarified by future research.

The origin of unequal working conditions lies in the model of capitalism and the type of social organization in the division of productive and reproductive tasks. The similarities found between the two countries therefore transcend the particular stage of economic development and the structural model of the economy. Fiscal, economic and labour policies and social welfare models naturally play a decisive role in correcting and reducing inequalities, as shown in the previous chapter. The pressing reality requires major reforms to prevent and eradicate these extreme situations and to offer decent jobs with guarantees for independent social life without deprivation. Passive and active labour market policies should be designed to pursue this objective of improving the quality of work and mitigating the effects of segmentation. However, if the policies reproduce the employment model and the productive structure that encourages it, they will not be sufficient to change the direction and avoid underemployment of the more educated population. In the long term, in order to reverse the inefficient and unequal productive and occupational realities that persist over time in both countries, policymakers will have to design structural reforms in combination with other coordinated policies of public and private investment in the economic, social and employment sphere. For this change of direction, the solution must also include bargaining and agreements between the social partners.

The following table shows some proposals for public policies aimed at dealing with inequalities in this area:

\section{Phenomenon analysed}

Inequalities in a segmented labour market

\section{Inequalities observed}

The general objective is to reduce the segmentation of the labour market in order to favour stabilization and reduce or eliminate work trajectories of inactivity, unemployment and job insecurity, thus reducing the gap between the primary and secondary segments of the labour market (Eurofund 2019) and generalizing decent work (ILO 1999), also the objective of the United Nations 2030 Agenda for Sustainable Development.

Most important policies for addressing these inequalities 
(a) Active employment policies aimed at the most vulnerable groups (youth, women, immigrants, people without training and with limited resources) to promote the acquisition of the skills necessary for employability with the best possible conditions. These policies should be accompanied from the demand side by incentives towards employers to hire and stabilize people with these vulnerability profiles.

(b) In particular, in relation to the qualification needs of the workforce, training policies for employment should be aimed at training the population, especially the most vulnerable people with low educational levels, to help them adapt to technological changes and labour demand through lifelong learning programmes. Vocational training should be aimed at improving the employability of a large number of workers.

(c) From the point of view of labour market regulation, limits should be placed on regulatory policies that favour the use of contractual flexibility as a business strategy of cost reduction and precarious employment, especially in low-productivity sectors, taking into account multi-layer subcontracting in particular.

(d) The unequal conditions of employment generated by labour segmentation require compensatory policies in relation to the low individual and family income with which the secondary segment is associated. To this end, the establishment of an appropriate minimum salary would attenuate wage inequalities generated by labour segmentation.

(e) The implementation of policies aimed at progressively changing the patriarchal and androcentric model of social life is a sine qua non condition for reducing equalities in the labour market. The equalization of men and women in the labour and non-labour sphere must be fostered through the reduction of wage gaps, work-life balance, incentives, positive discrimination policies, provision of services to families, time use policies, etc.

(f) Finally, there is a need for a long-term active industrial policy aimed at reorienting the productive structure towards the sectors with greatest productivity and added value, as well as financial policies that help sustain these changes.

\section{Important bodies for carrying them out}

It is important to promote social dialogue and reach agreements with the social agents and representatives of civil society to achieve commitments to structural changes maintained over time regardless of the ups and downs of electoral and economic cycles. These policies should be adapted to each socio-economic context to take into account the particularities of supply and demand factors that affect the segmentation of the labour market.

Source: P. López-Roldán, R. Semenza and A. Salvia (Chap. 3)

\subsubsection{Inequalities in Compared Educational Systems}

A comparison of three countries with very different social and educational situations serves to illustrate common and diverse dynamics in educational systems. Finland has a long tradition in providing public education, an advanced economy and an education system that has been taken as a worldwide reference after the standardized PISA evaluations. Spain has greater economic backwardness, and although its economy has grown rapidly in the last few decades, it was seriously affected by the economic crisis of 2008. Brazil has an economy that is growing strongly but it started from very low levels and is subject to great regional dispersion, to the point that it is like a small continent. Its education system did not reach 
broad sections of the population until relatively recently, and it still has many problems in reaching all social strata and in equality.

Despite the great differences, there are a number of common elements in the three countries. First, a discourse that values education and is guided by the theories of human capital prevails in all three countries; this discourse counteracts, to a greater or lesser degree, a discourse that sees education as a source of citizenship. Second, there is an ambition towards equity in education, although in different ways, e.g. by promoting public education with greater intervention by the State, regulating private schools with public funds and guaranteeing access quotas for students from the most disadvantaged sectors. Third, all three countries have witnessed an education expansion, an increase in female students at all levels of education, and social mobility. However, educational trends and debates in the countries take different forms because of their different historical, economic and social backgrounds and situations.

The global perspective of the three countries also serves to observe the level of discussion and variation in the consensus about the education system over time. Brazil represents an initial phase, with some setbacks which have already been overcome in Spain. Finland stands as an extreme case of an example to follow to reach the maximum education levels. However, it also demonstrates that the conquests and wide consensus attained by citizens can also be destabilized by educational reforms that introduce individualized principles instead of continuing to underscore criteria of collective equality.

Finally, global trends such as educational expansion, feminization of education and a market-oriented, neoliberal discourse in education policies are observed. How these trends are manifested in different societies varies because of their particular social, economic and cultural histories and circumstances. An analysis of statistics and policies reveals certain similarities and differences, but understanding them, the reasons for them and their effects and impacts on each society would require thorough qualitative case-oriented comparisons of the education systems and inequalities in education in their proper historical, spatial and societal frameworks.

The following table shows some proposals for public policies aimed at dealing with inequalities in this area:

\section{Phenomenon analysed}

Education in Finland, Spain and Brazil

Inequalities observed

Inequalities in educational systems: primary, secondary and higher education

Most important policies for addressing these inequalities

(continued) 


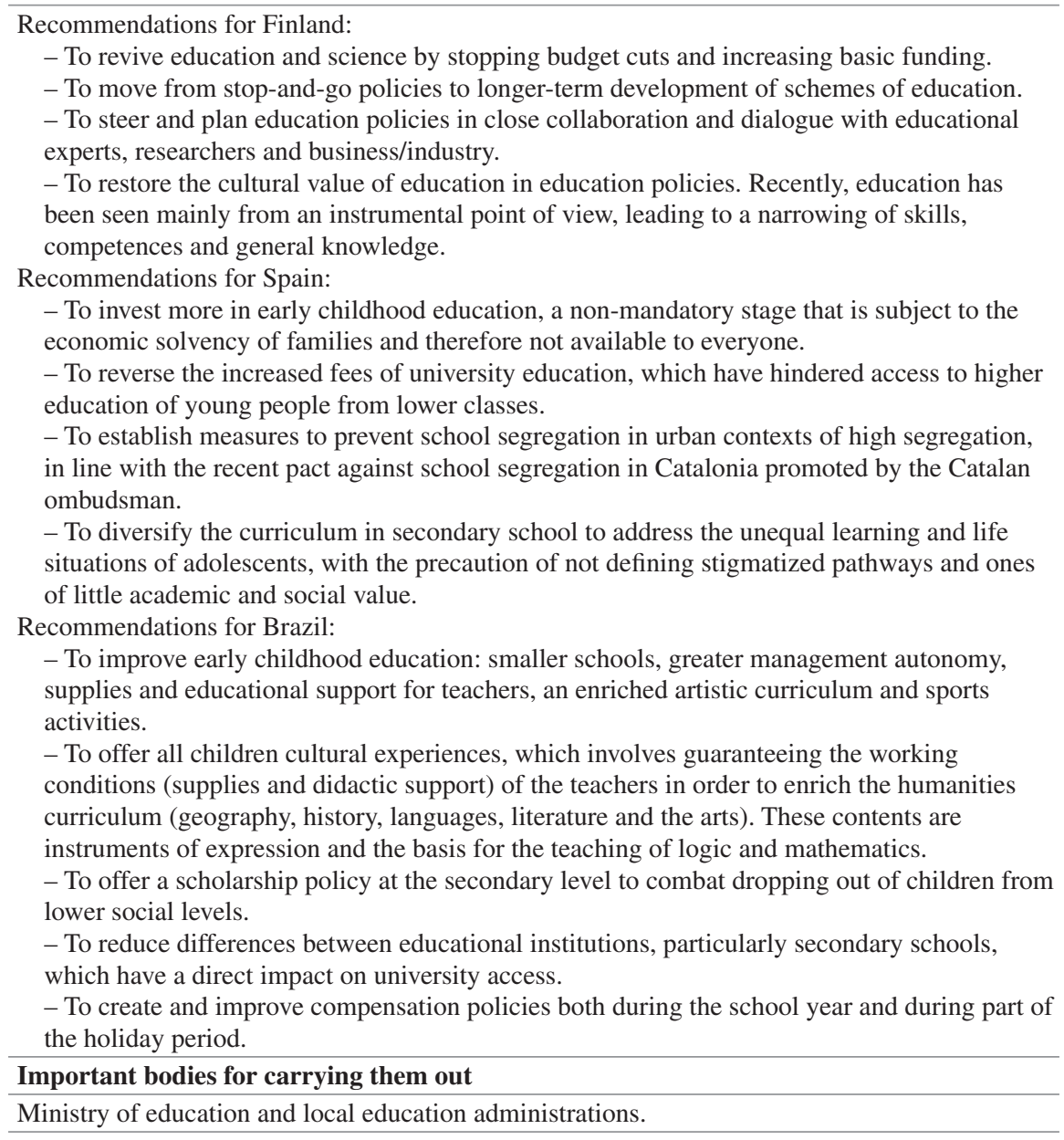

Source: J. S. Martínez García, E. Oinonen, R. Merino and G. Peroza (Chap. 4)

\subsubsection{Sociocultural Changes of the Digital Revolution}

This chapter summarizes how the economy is likely to evolve in the field of employment, skills and everyday life in the INCASI project countries. First, the indicators on the risk of job loss or job insecurity show that bad jobs (underemployment and informal employment) are dominant in many countries with and without digitalization, but mainly without it in Latin American countries. Second, the risk of job losses in more routine tasks (leading to unemployment and, in part, to underemployment) is high in all Latin American countries and in Spain and Italy, probably because of their productive structure and their subordinate position in globalization, which increases the risk of routinization. Poor employment and unemployment lead 
to low wage costs, hence a lower risk of effective robotization, especially in manufacturing, and particularly in the automotive sector, which accounts for a small share of jobs in most countries. Employment in the information and communication technologies sector is often a strong indicator of improved employment for countries where the digital economy is advancing. Bad jobs and unemployment will remain real threats, even if they are curbed by robotization.

In the field of education and training, the importance of having the highest level of education to deal with advances in digital technologies must be stressed. There is a growing time lag between labour supply and demand: people's times and the times of change in jobs. The differences between countries are considerable, not only between the two groups analysed but also within each group. Lifelong learning will undoubtedly become more and more important in the coming years because of the transformation of employment. The relationship between education and work that this time lag entails requires a new concept of schooling and training and, consequently, a change in the functions and organization of the institutions that offer them. The main changes are (a) conceiving education as a lifelong process and (b) focusing initial education (learning during childhood and youth) on laying the foundations and irreversibly providing the tools to make lifelong education viable for all. Schooling and training must be conceived as a process that will continue throughout life. This will be a complex process involving non-linear school and training experiences that will flexibly combine schooling, training and work experience. The conclusions highlight that the digital economy is being shaped in today's society, occupying an increasingly hegemonic space in the activities and organization of companies, jobs and daily lives. It will not advance at the same pace in all countries and will not embrace the whole of society. Comparisons between countries therefore make sense, as there are differences between men and women, between companies of different sizes, between education systems and others. Digital technologies develop in a particular social context, so interests, strategies, the associative fabric and the cultural, social and political traditions will play a role in their evolution. All these possible determinants of the advancement of digital technologies and their consequences for the everyday lives citizens are grouped into the notion of policies (standards, public funding, government actions and strategies of social actors) and the role of formal and informal education.

Related to everyday life, the increase in the use of the internet, smartphones and social networks (or rather, digital networks as this chapter calls them) is leading to important changes in communications, social relations, leisure, shopping habits, etc., which have shown a dramatic leap in all countries since 2005. The data show that the consumption or adoption of these digital technologies was consolidated at the beginning of this decade through a disruptive dynamics of convergence of these three technologies, which began to be used by individuals and households on a large scale and spread rapidly in all the countries analysed. This profound social change brought about by digital technological transformations all over the world, and particularly in the ten countries, has led to a socio-technological change arising from the massive individual use (consumption) of the three technologies: the internet, smartphones and social networks. 
The following table shows some proposals for public policies aimed at dealing with inequalities in this area:

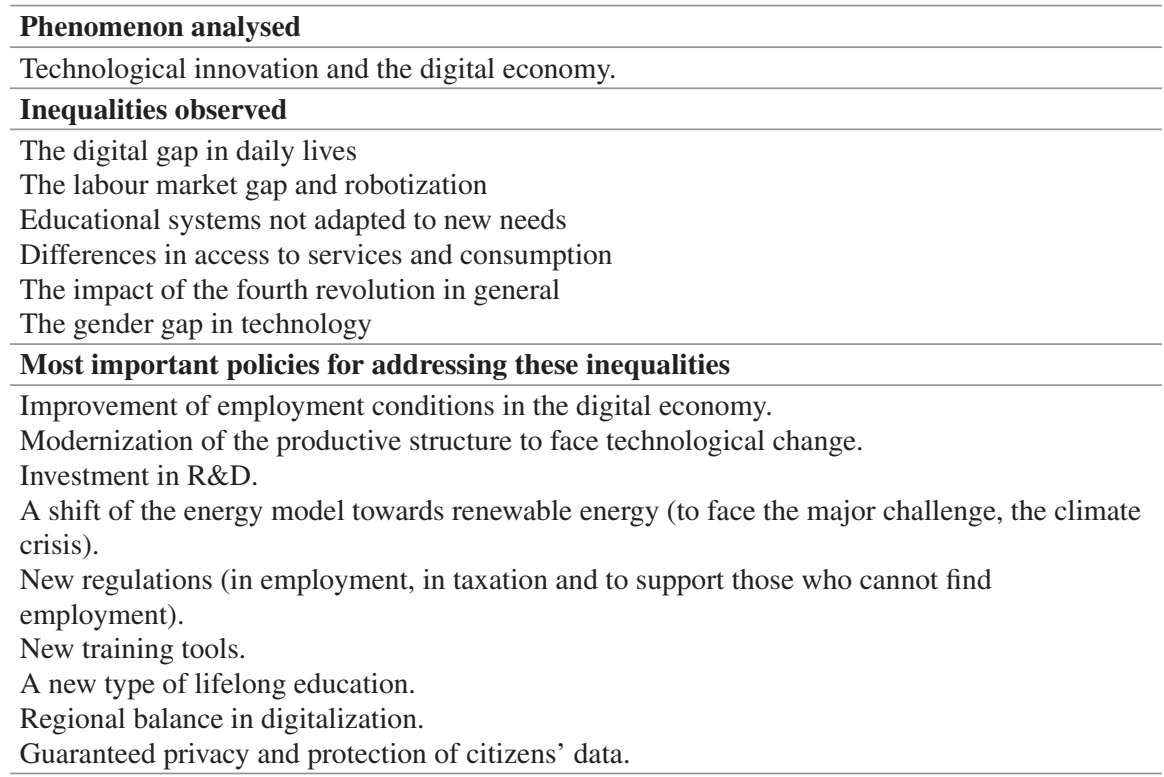

Important bodies for carrying them out

Governments in collaboration with different sectors of the economy.

Source: F. Miguélez, J. Planas and P. Benítez (Chap. 5)

\subsubsection{Social Stratification and Mobility}

\subsubsection{Measuring Social Stratification}

A comparison of social stratification in three Latin American countries (Argentina, Chile and Uruguay) and four European countries (Finland, France, Spain, Great Britain) is used to explore external and internal borders of social classes and the challenges posed by their analysis for sociology. Following the thesis of Treiman, who states that employment follows the same order in all societies, the analysis sought to determine how similar the social classes in Europe and Latin America are.

The classification of Erikson, Goldthorpe and Portacarrero provides a good picture of the class structure in different countries. The first conclusion to be drawn is that despite different historical trajectories, welfare regimes and development levels, the structure of social classes is very similar. However, differences can also be seen. In advanced economies a large proportion of the population are in the service class. Since the living conditions of this class are much better than those of the other social classes, a large section of the population of these societies has high standards 
of living. Likewise, there is a larger agricultural population in Latin American countries, and two countries that underwent late industrialization, Finland and Spain, still have a large agricultural sector. Segregation according to gender is also widespread.

The second conclusion refers to the education level attained by the different social classes. Educational growth has been more intense in Europe and has reached a higher number of social classes. It has also been attained particularly by women in Latin America. The third conclusion is that there are some divergent points in the employment conditions of the social classes between Europe and Latin America. The working conditions of Latin American countries are worse than those of their European counterparts, including those in Southern Europe. On a scale from more industrialized to less industrialized economies, fewer social classes reach adequate work conditions and decent life opportunities.

Finally, different numbers of classes also indicate different levels of inequality. Europe's citizens form part of three large groups, while Latin America has greater stratification between its classes. In general, the role of the State does not appear to modify the social class structure in the societies analysed, which are characterized by a market economy and nuclear families. However, according to the level of development, a larger proportion of the population seems to have better social opportunities.

The following table shows some proposals for public policies aimed at dealing with inequalities in this area:

\section{Phenomenon analysed}

This chapter compares social stratification in three Latin American countries (Argentina, Chile and Uruguay) and four European countries (Finland, France, Great Britain and Spain).

\begin{tabular}{l}
\hline Inequalities observed \\
\hline $\begin{array}{l}\text { Greater differences between social classes in terms of education, income and other goods and } \\
\text { services. }\end{array}$ \\
\hline Most important policies for addressing these inequalities \\
\hline Educational expansion in order to increase skills for work \\
Lifelong learning inside and outside the workplace \\
Compensatory policies for women \\
Work-life balance policies \\
Compensatory policies for low-class workers
\end{tabular}

Important bodies for carrying them out

The ministries responsible for employment

Source: E. Barozet, M. Boado, I. Marqués-Perales (Chap. 6)

\subsubsection{Comparative Social Mobility}

The relationship between social origin and class destination in the ten countries of the INCASI network was analysed in order to find a relationship between the level of development and social mobility. 
The conclusions regarding absolute mobility are that structural change has been very great in both Latin American and European countries. There is greater similarity in the class movement in Europe, whereas the changes are more abrupt in Latin America. There are two different stages of industrialization according to Ishida and Miwa, which can be summed up as high rates of deruralization in late-industrialized countries and a more marked process of deindustrialization in European countries. The growth of the service class shows the accentuation of the post-industrial stage in Europe; this phenomenon is also observed in all Latin American countries but to a lesser extent and with greater differences between countries. Considering absolute social mobility in a more compact way, by collapsing the seven classes of the social class scheme of Erikson, Goldthorpe and Portocarrero to four macro-classes, reveals the importance of immobility because it indicates the strength or inertia of social reproduction. Women are the most upwardly mobile (43.6\%), whereas close to $17 \%$ of the general population suffered downward mobility.

The results for relative mobility confirm that European countries are more fluid than Latin American countries. When differences between classes within each country are studied without taking them comparatively, a common hierarchical order is observed that shows the agricultural classes at one end and the service classes at the other end, indicating the polarization between classes, and various intermediate situations according to the particularities of each country. Men in Brazil and Chile and women in Mexico and Chile show the greatest relative inequalities. On the other hand, men in Italy, Spain and Great Britain and women in France, Great Britain and Finland show the lowest inequalities.

When all countries were placed in relation to each other, a comparative relative inequality measure between classes and between countries was obtained. The results show that relative mobility between classes is much less frequent in Latin American than in European countries. In particular, in Brazil, Chile and Argentina the mobility barriers are very high for men and even higher for women compared with the other countries.

A separate analysis of class inheritance corroborated a pattern of uniform behaviour in all countries, revealing the class of small farm owners to be the most reproductive in all countries. The class that contributed least to reproduction was the lowest one, that of agricultural labourers.

Finally, the analysis provides evidences, that "the later and faster the industrial development, the higher the social inequality and the lower the social fluidity", in line with the hypothesis of Ishida and Miwa. The most important result was that the measure of social inequality is purely sociological, based on socio-occupational indicators.

The following table shows some proposals for public policies aimed at dealing with inequalities in this area: 


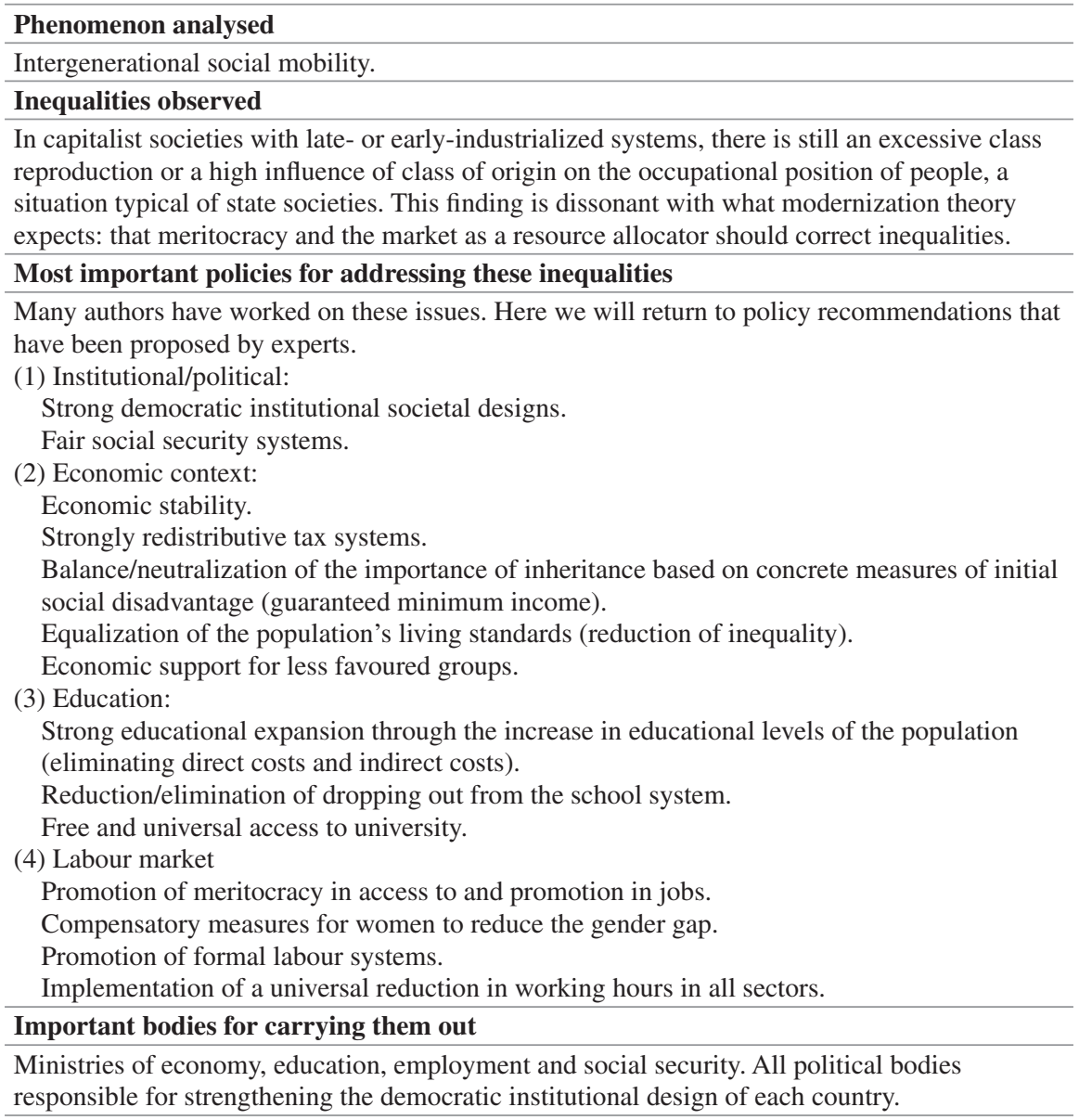

Source: S. Fachelli, I. Marqués-Perales, M. Boado and P. Solís (Chap. 7)

\subsubsection{Migration, Social Mobility and Transnational Space}

The relationship between migration and social mobility in two countries, Argentina and Spain, was analysed from two perspectives: through a transnational study of the patterns of intergenerational social mobility of immigrants and natives in these two countries; and through a study of the social mobility strategies and trajectories of Galician families in Buenos Aires and Argentinians of Galician origin who migrated to Galicia after the 2001 crisis.

The transition towards market-based capitalist agriculture and developments in sea transport led large numbers of displaced agricultural workers in Europe to move to the United States, Canada and Latin America. Latin American countries-and Argentina in particular-held an irresistible appeal for overseas immigrants in the wake of waning migratory flows from northern Europe and a rise in the number of 
migrants travelling from Southern Europe. This situation changed totally from the mid-twentieth century onwards, with a rise in interregional flows, a steady fall in the total and relative number of overseas immigrants, and extra-regional emigration to more developed countries (the USA and Europe).

In both Spain and Argentina, the integration of the immigrant population now falls within a polarized class structure in keeping with the dynamics of modern-day capitalism. Essentially, immigrants provide the workforce that satisfies the demand for unskilled manual labour. This trend is slightly more evident in Spain, where the class structure is more consolidated. As entry is made into the lower echelons of society, the immigrants generate a kind of "upward push" for the native population of both countries. In addition to this general common trend, immigrants in Argentina display a higher rate of upward social mobility than their counterparts in Spain, which can be attributed to the fact that they originate from lower classes. Furthermore, immigrants in Spain enter a more consolidated class structure and may be faced with greater levels of discrimination. However, though they occupy lower rungs on the social ladder, they obtain higher incomes than in their places of origin.

Historically, Spanish emigration to Argentina has provided opportunities for upward social mobility, attributable to a series of factors that include a less consolidated social structure, migratory policies that favoured the arrival of overseas immigrants and a Euro-centric imaginary and habitus oriented more towards material accumulation. In contrast, the Latin American immigrant population in Spain and regional immigration in Argentina are today a source of manual/unskilled labour within a context of more consolidated social structures, a segmented labour market and migratory policies that are traditionally more restrictive towards subordinate ethnic groups.

A reflection on the link between social and spatial mobility is presented. Migration has a positive effect on the social mobility of the native population, but it also has the capacity to reproduce social inequality for the migrant population within a context of more closed social structures and restrictive migratory policies. This situation blocks migrants' dreams of social ascent due to the ethnic segmentation of the labour market. Nevertheless, a study of the relationship between migration and social mobility from a transnational perspective that looks beyond the host country reveals the social mobility strategies that activate different forms of capital, passed down from generation to generation (economic/asset-based, social, ethnic and citizenship-based) within the transnational space, that enable migrants and their descendants to tackle the social blocking and "immobility". They transport a baggage filled with capital in varying forms that travels from one side of the Atlantic to the other, allowing them to achieve dreams of social mobility.

The following table shows some proposals for public policies aimed at dealing with inequalities in this area: 

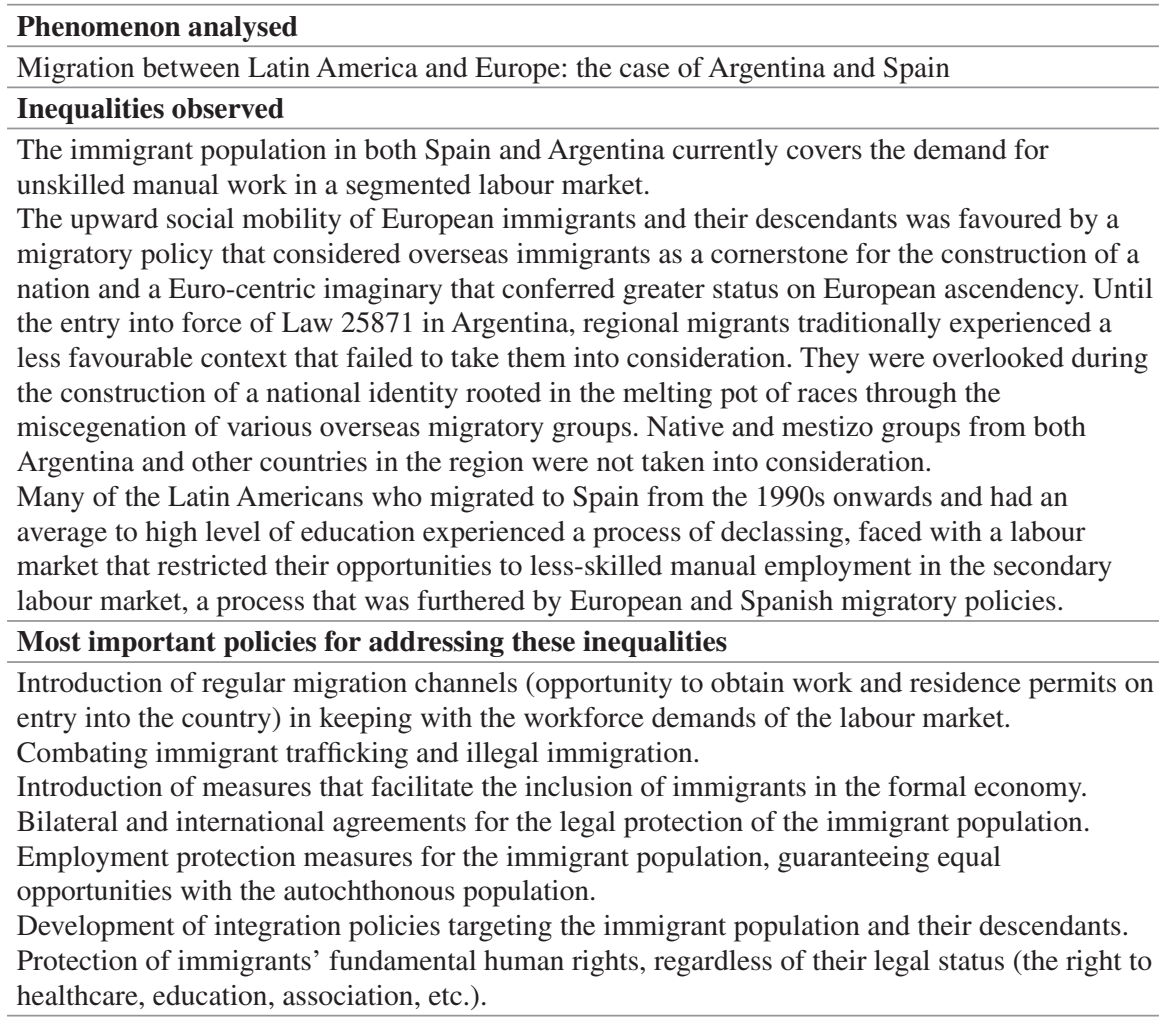

Important bodies for carrying them out

European Union, Mercosur, States, regional/autonomous governments, local governments

Source: L. Oso and P. Dalle (Chap. 8)

\subsubsection{Economic Inequality}

This chapter compares structural differences and changes in income distribution during the twenty-first century in a selection of countries in Latin America and Europe, as well as within and between the two regions. It considers how unequal the trends towards equality or inequality in income distribution are between Latin America and Europe and explores some factors that could determine this distribution of income within each country and in both regions.

The results show that while GDP per capita has increased in both the individual regions and in the aggregate, the differences between Europe and Latin America persist: the mean for Latin America remains about one third of the mean for Europe. Likewise, the coefficient of variation has decreased in Europe but has increased in Latin America, illustrating an increase in inequality between Latin American countries in terms of mean income per capita. The coefficient of variation shows a significant reduction in poverty over time both by region and in the aggregate of countries. Europe has clearly lower poverty rates, although with greater intraregional variation. In Latin America, on the other hand, the trend seems to have been 
markedly positive, with less internal variation but with an increase in inequality between countries. Finally, the Human Development Index (HDI) shows an improvement, with a reduction in inequality between countries in each region, between regions and in the aggregate. However, Latin America still has far lower levels than Europe, and the gaps between countries have narrowed less than in Europe.

Income distribution within each country is the product of the complex interaction of innumerable economic, demographic, social and institutional factors. Inequality in income distribution among the population globally or within a region reflects the combined effect of inequality within countries and inequality between countries. Seen in this way, the simplified description of the behaviour of global inequality over the past hundred years shows a period of declining inequality within countries, but with an increase in the gap between countries. More recently, the trend has been different, at least for the countries of Latin America and Europe: inequality in income distribution tends to increase in some societies and to decrease in others, narrowing the gap between countries in each region and between regions.

Taking into account the three variables (the Gini index, productivity and social spending), the results show that, in general, Latin American countries are located in the "lower development with greater distributive inequity" group and European countries are located in the "greater development with lower distributive inequity" group.

Finally, the study provides evidence in favour of a reduction in economic inequality between regions but also shows the existence of structural factors that could explain intra-regional distributional inequalities that are still great.

The following table shows some proposals for public policies aimed at dealing with inequalities in this area:

\section{Phenomenon analysed}

Inequalities within countries and between countries and regions.

\section{Inequalities observed}

Inequality has tended to increase within countries recently, but the gap between countries has narrowed (Atkinson 2015).

During the last two decades of the twenty-first century, Western Europe and Latin America narrowed their economic inequality gaps because they followed different paths: while inequality narrowed in most Latin American countries, the opposite occurred in most of Europe.

In Europe, we see a double effect of inequality. While the process of European economic integration consistently reduced inequalities between nations into the first decade of the twenty-first century, convergence was partially interrupted by the effects of the 2008 economic and financial crisis and by austerity policies.

In GDP per capita, while both the individual regions and the aggregate have improved, the differences between Europe and Latin America persist: the average for Latin America remains about one third that for Europe.

The HDI shows an improvement, with a reduction in inequalities between countries in each region, between regions and in total. However, Latin America still has far lower levels than Europe, and the gaps between countries have narrowed less than in Europe. 


\begin{abstract}
Most important policies for addressing these inequalities
To improve secondary distribution in order to achieve real improvements in terms of material well-being and to assess how to implement social policies according to the proportion of social spending in each country.

To broaden the level of coverage of social policies associated with secondary distribution of national income and income redistribution.

To evaluate the implementation of, for example, minimum guaranteed employment programmes, in which the government should adopt an explicit goal to prevent and reduce unemployment, offering jobs that guarantee a minimum wage to those who seek them, mainly by targeting these jobs to the informal and social economy sectors.
\end{abstract}

\title{
Important bodies for carrying them out
}

A minimum guaranteed employment programme would require the coordination of several bodies:

In Argentina, for example, the Ministry of Social Development, the National Council for the Coordination of Social Policies, the Ministry of Labour and the National Social Security Administration.

In Spain, for example, the Ministry of Labour, Migration and Social Security and the State Secretariat for Social Security.

Source: A. Slavia (Chap. 9)

\subsubsection{Life Trajectories and Gender Inequality}

\subsubsection{The Life Course Perspective for the Analysis of Social Inequalities}

To analyse social inequalities in our model, the importance of dynamic and temporal aspects was established in terms of either trajectories or mobility, also taking into account biographical aspects. The diachronic dimension of inequalities must be considered, because it identifies the way in which inequalities increase or decrease over time, and how they are reproduced and transmitted between generations. With this objective, a theoretical-methodological proposal was developed that seeks to make compatible and articulate macrostructural conditions (the macrosocial scale), institutional relations and policies (the mesosocial scale) and the actions of individuals (the microsocial scale) in the study of social inequalities. The particular combination of multiple scales and dimensions over time and in specific contexts (historical, cultural, etc.) leads to a permanent production and reproduction of social inequality. The biographical perspective proposed by Bertaux, or the life course perspective proposed by Elder and other authors, are therefore intrinsically diachronic and offer methodological advantages that make this approach possible.

In particular, taking into account the holistic case studies proposed by Yin, a biographical comparative approach is developed. This approach can be intraconfigurative and interconfigurative. The intraconfigurative biographical approach involves taking a biographical case, i.e. a unique case, and analysing the articulation/tension of the macro- and mesosocial scales over time, i.e. the way in which factors external to the subject affect the life trajectory and the role played by 
subjective experiences and decisions in its development. The biographical account of the social actor is recovered as a source of fundamental information. The choices and actions deployed and the consequences of certain structural constraints are observed in the biographical narrative, and the researcher incorporates an analytical approach into the particularities of the macro- and mesosocial scales in the configuration of the biography studied. The interconfigurative biographical analysis involves a comparative case study in which two or more biographies are contrasted. The analysis considers, first, the way in which macro- and mesosocial scales affect the development of the life trajectories in each case; second, the relevance that the experiences and choices of the subjects have in their life path; and third, the particular external constraints and actions in the different stages of the trajectories.

As has been demonstrated from the analysis of the cases, the comparative biographical perspective and its intra- and interconfigurative analyses allow us to constrastively establish the particularities of external constraints and subjective actions in the different stages of the compared life trajectories. This perspective highlights the importance of the voice of social actors for understanding how different trajectories are constructed in the face of similar or different macro- and mesosocial contexts that are the result of a chain of advantages or disadvantages that configure and reconfigure social inequalities over time.

The following table shows some proposals for public policies aimed at dealing with inequalities in this area:

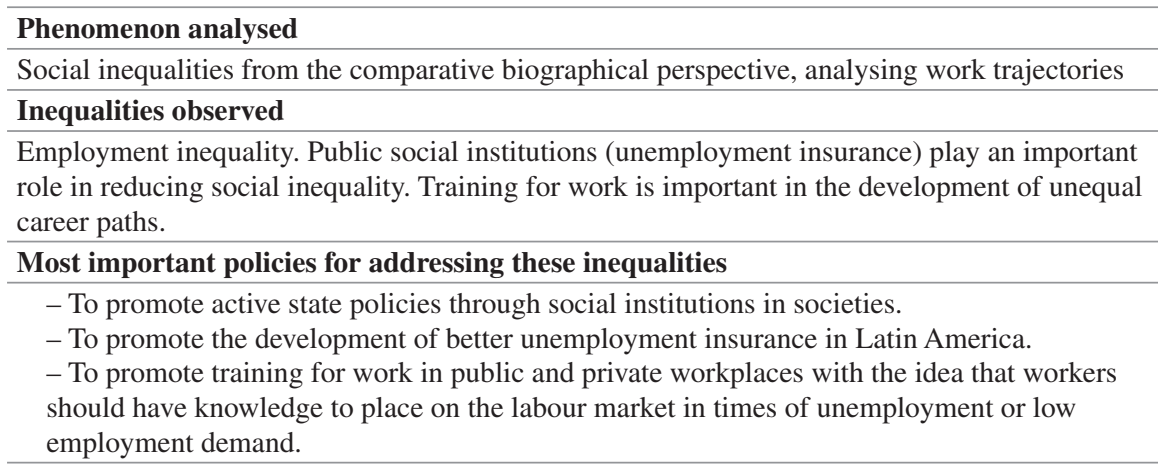

\section{Important bodies for carrying them out}

The administrative bodies in each country responsible for social protection, labour and macroeconomic policies.

Source: L. Muñiz-Terra and J.M. Verd (Chap. 10)

\subsubsection{Social Times, Reproduction and Social Inequality at Work}

The analysis of social times and inequality, focusing on changes in the use of time and social inequality in unpaid work between men and women, reveals the need to design and implement public policies that relate working time to the principle of 
equality. Although models of traditional male-provider families in which women play a dual role remain dominant in some countries, some changes are observed in the hours spent on paid and unpaid work in dual-income heterosexual couples, reflecting patterns of transformation of women's participation in the public sphere. It is concluded that reducing gender gaps in non-reproductive working time will involves addressing domestic co-responsibility, agreed organization of working time and accessibility to social and care services for children and older adults. Discussions on productive and reproductive work take on new significance when demographic, social, economic and political changes in contemporary societies are analysed. The position of women in the productive sphere and their economic participation in the labour market are related to how reproductive work issues are resolved individually and socially and how they are linked to the commodification of care work.

The time use methodology, and in particular time use surveys, were embedded in the debates that, from a critical feminist position, influenced the conceptualization of time as invariable, homogeneous, independent of the context and set against a commodified money time that is dominant, recognized and valued. In addition, this time reflects power structures and capitalist and patriarchal relations. Although a reduction in gender differences in time use has been detected over the past 50 years, women have a higher overall unpaid workload and total time worked than men in all countries, highlighting the significant feminization of unpaid work and the persistence of gender segregation in relation to domestic work. The differences between countries in the hierarchy and the magnitude of the most relevant factors for explaining the gap between men and women are noteworthy and the Latin American countries show greater differences in the gender gap than the European ones. The analysis of the gender gap in domestic and care work shows the low incidence of the variables related to "relative resources": women's education levels, socio-professional categories and economic resources in the capacity for negotiation and in the distribution of time dedicated to this work. But their participation in paid work and their economic income are relevant factors for reducing the inequality gap, thus verifying the association between the socio-economic stratification of women and gender relations. By contrast, men's relative resources, education level and socioprofessional category are more consistent and of a higher level, especially in Latin American countries. Therefore, the inequalities in the social relations of production intersect with the maintenance of relations of gender inequality. Consequently, women from lower classes and more disadvantaged households suffer greater inequality in unpaid work in households.

Taking into account gender ideologies, roles and attitudes underlying the sexual division of work and the gender gap in carrying out of domestic and care work, androcentric cultural and social norms and values persist to a greater extent in Latin American countries. In all countries, women dedicate more time to domestic and care work in accordance with the care and welfare needs of the people in the household. The gender gap is sensitive to this and shows that female time is the adjustment variable, with consequences on the quality of life and welfare of women, and male time is the key factor to achieving equity in work times. 
The following table shows some proposals for public policies aimed at dealing with inequalities in this area:

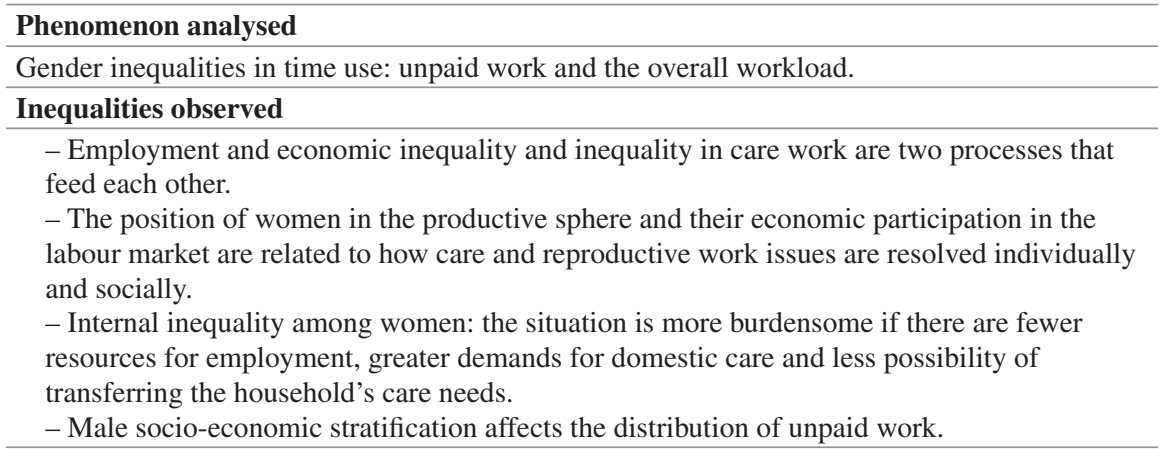

\section{Most important policies for addressing these inequalities}

- Work-life balance measures: parental leave, elderly care, etc. Gender-sensitive publicly funded leave policies (for childbirth, illness or care of dependent persons) for all men and women.

- Active labour market policies: incorporating unpaid carers into the labour market.

- Promotion of equal working conditions for women, in particular equal pay and equal access to retirement and pensions.

- Promotion of men's participation in care work within households. Recognizing, reducing and redistributing unpaid care work.

- Rewarding: more work and decent work for care workers.

- Planning of working times more in line with social times (reduction of working hours, adaptation of working time to school time).

- Investment in quality care services, policies and facilities.

- Ensuring full and effective participation of women and equal opportunities for leadership at all levels of decision-making in political, economic and public life.

- Education in equal social values.

- Regulation of domestic workers, maternity protection and wage equality.

\section{Important bodies for carrying them out}

Social protection policies, labour policies, care policies and macroeconomic policies to be carried out by the relevant political and administrative bodies.

Source: M. Domínguez-Amorós, L. Muñiz-Terra and G. Rubilar (Chap. 11)

\subsubsection{Gender and Care Models}

This chapter presents and characterises the way in which, in the twenty-first century, after years of feminist struggles inside and outside of institutions, gender relations are organised in the different countries: on the European side, Spain, Italy, Finland, France and the United Kingdom; and on the Latin American side, Argentina, Brazil, Chile and Uruguay.

Gender relations can be understood as a relevant category of analysis for understanding social protection systems and their evolution in the neoliberal era. Despite the shared legacy of the male breadwinner/female carer model and the widespread 
emergence of the adult worker (or dual earner) model, all countries are organized on the basis of different principles and different national gender equality architectures that can be identified as "gender regimes". Gender "contracts" or "regimes" emanate from the degree of defamilization and the social organization of care, i.e. the state policies adopted (or not) to free women from domestic and family responsibilities, which remain a female prerogative.

From the institutionalization of state feminism in the 1990s in Europe and Latin America, the defence of women's interests - understood as a social categoryobtained the status of an important political issue in certain public and especially international institutions, formalizing the perspective of gender mainstreaming. However, state feminism did not generate the adherence of the entire feminist movement. Nor did it lead to the same dynamics or have exactly the same consequences on the two continents studied. And its degree of implementation in different countries says something about the state of gender relations, in particular in relation to the analysis of state regulation of care.

The positioning of different countries regarding the type of "gender contract", mostly established according to the level of deinstitutionalization of the male breadwinner model, is an important indicator of advances in gender equality. It is a starting point for deciphering the state of gender relations in countries where gender issues are presented differently. It allows a comparison of the importance given to the transformation (or not) of the sexual division of labour by the feminist movement or by the institutions in the countries of the two continents. But, above all, the integration of Latin American contributions into European analyses allows the analytical framework to be renewed and adapted to a new social reality. This is especially the case with regard to the introduction of the issue of social equity in a context of multiple crises of capitalism.

However, improvements in gender gaps and, in particular, increased participation of women in the employment market and the decline in the male breadwinner model now face the risk of "redomestication" of women as a result of the emergence of populist right-wing, exclusive and totalitarian systems, or neoliberal projects that fail to carry out policies that maintain the improvements achieved. The labour market has also deteriorated considerably, bringing the new European gaps closer to the structural ones in Latin America, segmenting the situation of women between a group of privileged people who have more and more opportunities to enjoy the advances of the salary society or economic power and a disadvantaged group in their working and employment conditions that cannot enjoy the long-awaited social protection of salaried societies. Structural changes in terms of gender seem to be affected, threatening the rights and living conditions acquired so far by women, especially the less privileged.

The following table shows some proposals for public policies aimed at dealing with inequalities in this area: 


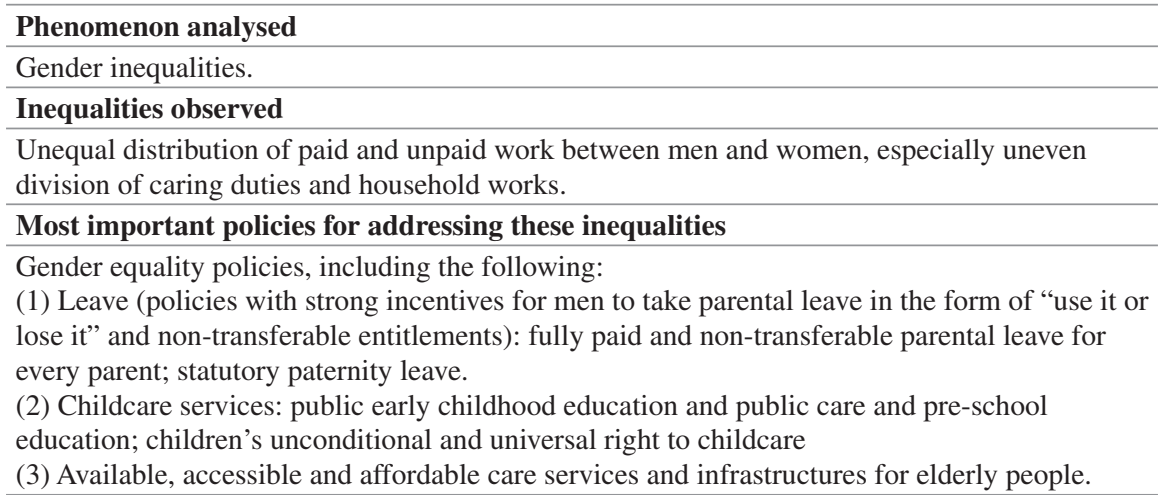

\section{Important bodies for carrying them out}

Gender equality machineries, such as a full ministry dedicated to this question.

Source: J. Jarty and K. Batthyány (Chap. 12)

\subsubsection{Social Policies}

\subsubsection{Unemployment Benefit Schemes}

In relation to social policies, an initial analysis gave a comparative perspective of the unemployment protection systems in Argentina, Uruguay, Spain and Italy. Despite the similarities because all are compulsory, contributory and proportional, they operate differently depending on the contexts of employment (more or less informal), the rate and coverage of unemployment, and the amount of precarious employment in each country.

The theories of the active social state and the investor state and reforms of unemployment protection systems have led to the adoption of modernizing language in these countries: activation, employability, conditionality, life-cycle training and flexibility are some of the words used in Europe and also in Latin America, but with different meanings according to the institutional reality of each country. In the Latin American countries, the welfare state is very weak, whereas in Europe it is a diverse institution. Nevertheless, a common trait of the four countries is a trend towards increased welfare policies, in line with the increased risk of poverty.

The conclusion is that the four countries show some similarities in their trends: (1) welfare policies have increased; (2) the third sector has grown to address inequalities and the risk of poverty in the face of the withdrawal of the state; (3) in all four countries the high volume of public debt restricts the possibilities of political manoeuvre; (4) because the states are indebted, the responsibility for job creation lies with the market rather than public intervention; (5) a discourse aimed at coordinating passive and active policies has been introduced, even with a certain degree of conditionality for the unemployed to be able to receive benefits, although 
this discourse is still purely formal, far from reality; and (6) there is an emphasis on pre-distributive policies, focusing on activation in the labour market and emphasizing the idea that the first distributive social policy should be employment.

The difference between continents is that in Latin America informal employment reduces the coverage of unemployment benefit and also the powers of unions, whereas in Europe the unemployment coverage rate is high. In short, in Europe the administration and the fiscal system have a considerable capacity to monitor and sanction. In addition, strong trade unions have contributed towards the pressure to sustain the welfare state.

The following table shows some proposals for public policies aimed at dealing with inequalities in this area:

\section{Phenomenon analysed}

Unemployment benefit schemes in Spain, Italy, Argentina and Uruguay: similarities and differences in intervention and social contexts.

\section{Inequalities observed}

A low coverage rate of unemployment, informal employment and inefficient non-contributory benefit.

Weak collective bargaining and unemployment protection.

\section{Most important policies for addressing these inequalities}

- A higher coverage rate, regularization of informal employment and an improved noncontributory benefit policy.

The employment crisis forced many governments to introduce non-contributory systems. Many unemployed people exhausted their contributory unemployment benefits, which became a pressure factor to introduce new benefit systems or non-contributory benefits. This was the case in Spain during that period, with the approval of the Prodi and Prepara benefit programmes in 2011, in addition to other benefits reformed during the crisis. In Italy, the Reddito di Cittadinanza was approved in 2018. Many analysts have described this policy as "welfare-based" and aimed at avoiding the risk of severe poverty (Kazepov and Barberis 2013; De la Rica 2015).

- Collective bargaining and unemployment protection The coordination mechanisms are the level of collective bargaining and its degree of centralization, in addition to state regulation. We conclude that a social model is defined by the way in which pre-distributive and post-distributive policies are articulated, which led us to consider collective bargaining systems as important for reducing inequalities in the Gini index. Wage coordination through collective bargaining - and its broad coverage in the number of protected workers-introduces egalitarian wage patterns, as demonstrated in Scandinavian countries, which are described as strong neo-corporatist systems.

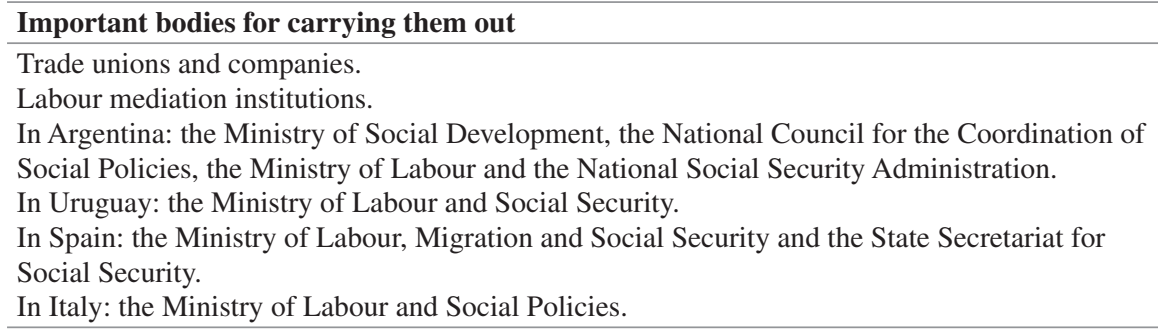

Source: A. Martín-Artiles, F. Vincenzo and E. Chávez-Molina (Chap. 13) 


\subsubsection{Compared Pension Systems}

A second analysis on social policies compared the pension reforms and current tendencies in two European countries, Spain and the United Kingdom, and two Latin American countries, Chile and Argentina. The hypothesis behind the study was that it is difficult to sustain strategies that involve a risk of dualization of social security schemes, de-linked from the principles of social rights and with a marked tendency towards increasing inequality.

The existence of a series of common elements is observed in the reforms implemented in European Union countries. The first measure is a policy aimed at diversifying financing so as not to depend on contributory pensions and the demographic effects of population ageing, as well as low wages. The occupational pension system (pensions financed by companies and often associated with collective bargaining) linked to employment has been growing in Europe. Pensions are also being financed through private pension systems, capitalization pensions. In some countries, this financing is linked to the "financial participation" of workers in the profits of companies.

The re-reform of the pension system introduced in Chile during the Bachelet government in 2008 tried to return to the role of the State as a guarantor of certain principles of universal rights and the creation of the Solidarity Pension System (SPS). Although the reform persists in sustaining the Individual Capitalization System of the old Pinochet regime, a series of changes were introduced that involve not only lowering costs but also achieving better pensions for members, as well as strengthening Voluntary Pension Savings (APV). The re-reform of the Argentine pension system evolved from a mixed system with a distribution and capitalization system established in 1992 to the 2008 pension reform, which reversed the private capitalization system and returned to the state distribution system. In January 2009, the Plan or Programme for Pension Inclusion was implemented, applying the strategy of expanding pension coverage through early retirement programmes or by moratorium in order to correct and increase the number of beneficiaries.

Finally, whatever type of pension reform is implemented, it must be debated publicly and widely. The trend towards capitalization systems finds a barrier in the widespread informal work in Latin American countries. As discussed in Chap. 2, the informal sector has grown exponentially in part due to labour flexibility, which is typical of the neoliberal policies applied in the region. Similarly, gender inequalities are on the agenda in both continents, and despite the differences that can be observed between European and Latin American countries, problems of parameters such as age and gender inequality persist. But it is perhaps the change in principles guiding social security through the international agreements established by the ILO that could lead to a paradigm shift.

Four important tendencies of the reforms involving the solidary principles of the system are pointed out: (1) the crisis of organic solidarity, which generates a return to mutual support, interfamily assistance and volunteering, and the growth of the third sector; (2) the crisis of inter-regional solidarity, especially in Europe with the emergence of the 2008 crisis, which has generated a rejection of transfers between 
rich and poor regions; (3) the crisis of inter-classist solidarity, expressed in the rejection of fiscal pressure and demands to reduce taxes; and (4) the crisis of intergenerational solidarity, produced by the wage devaluation of young wage earners.

The following table shows some proposals for public policies aimed at dealing with inequalities in this area:

\section{Phenomenon analysed}

Social policies and in particularly pension/retirement policies in a context of crisis and paradigm shift.

Inequalities observed

Inequalities in access to 'decent' pension/retirement schemes for all societal groups

Most important policies for addressing these inequalities

To democratize the access of disadvantaged groups to (distributive and post-distributive) pension/retirement schemes.

To adopt solidarity and inclusion rather than market-driven approaches.

Important bodies for carrying them out

State pension bodies.

Source: P. Scarponetti, L. Sepúlveda and A. Martín-Artiles (Chap. 14)

\subsection{Towards a Research Programme}

As a result of the work carried out within the framework of the INCASI project, we will propose for the forthcoming years a multinational comparative research programme on inequality and social stratification patterns in Latin America and Europe. The justification for this programme comes from the need to expand international comparative research to consider the way in which social inequalities are expressed in different national and regional contexts and to identify similar patterns and mechanisms inherent in the configuration of social inequalities. By comparing countries, we can recognize some similar historical processes, such as global economic integration, technological change and globalization, precarization of labour markets and gender inequalities. We can also observe dissimilar social and historical conditions marked by the specific characteristics of each region and country. Further exploration of these issues will guide the general objectives of the future programme.

With the concept of social stratification, following Grusky's definition, we refer to the set of social structures and institutions that regulate access to life opportunities, as well as to social mobility mechanisms that guide access to the positions defined by those structures and institutions. We will adopt a multidimensional approach to social stratification, which allows us to broaden our view beyond studies that emphasize an isolated dimension of inequality (for example, occupational or income hierarchies) and thereby try to capture more broadly the complexity of multiple inequalities and their interaction in specific social contexts. 
The development of a multinational and multi-thematic comparative research programme requires a general analytical framework broad enough to include the diversity of research themes and perspectives of the researchers participating in the project. This general analytical framework will be used to establish a set of basic principles that will guide the research work in each area, to which specific principles that are relevant in each research topic will be added. To this end, our starting point is the AMOSIT model, which served as a general analytical framework for locating the different lines of research of the INCASI network and constructing the first integrated conceptual scheme for the analysis of social inequalities. As we explained in Chap. 1, from the substantive point of view this model considers three central areas of social life in which we can study social inequalities in an interrelated way: the educational system, productive work and reproductive work. From the methodological point of view, we define three central aspects in our analysis model: the articulation of macrosocial and microsocial elements with mixed method analysis designs, the importance of the dynamic dimension of social phenomena over time and the comparative perspective between countries.

Taking into account this precedent, in the new research programme our general thesis is that to understand the similarities and differences in social stratification patterns between regions and countries, it is necessary to understand the interface between structural factors (such as the productive structure, the labour market, the gender model, the territory, demographic dynamics and technological change) and national institutional configurations (such as social models, educational systems, labour market regulation, social security systems and social policies). Regardless of the specificity of the issues that make up each of these areas, the analysis of gender and ethnic inequalities should be adopted as a cross-cutting analytical perspective. We must also study the interaction of the issues in terms of intersectionality, assuming that economic and social inequalities depend not only on the position that individuals occupy in the productive structure (their class position) but also on other factors or categories, such as gender and ethnicity, and jointly determine differentiated access to opportunities and resources. Thus, the research programme plans to perform specific analyses of the configuration of inequalities in several specific dimensions, such as educational and trajectory transitions, intra- and intergenerational social mobility, income distribution, use of time, migratory processes, agencies and strategies.

The research programme will demand the development of specific methodological strategies for each of the dimensions that arise from the specification of mixed analysis designs through the articulation of quantitative and qualitative methodological perspectives. Depending on the research questions and hypotheses in each dimension, the specific analysis design should detail the geographical scope of the study in terms of the countries included, the secondary sources of information already available that are useful for the investigation in question, the possible need to obtain primary information (and the characteristics of this information), and the data analysis techniques.

Further work on the comparative analysis between Europe and Latin America must also serve to generate more accurate diagnoses and more appropriate 
recommendations for designing public policies in the various fields. The ultimate goal remains the same: to provide tools for reducing social inequalities. The social world in which we live has maintained the reproduction of social inequalities as one of its constants over time, making it a structural and universal phenomenon. It remains one of the pending subjects of humanity. The programmatic objectives of the European Union and the sustainability objectives proposed by the United Nations, in addition to other similar proclamations, constantly remind us of the importance of this task. Combating social inequalities will require more and better social scientific research, as well as large data production to support it. But more important is the political will of governments and international institutions to adopt it as a priority and provide the effective means to for carrying it out. We hope that they will do so.

\section{References}

Atkinson, A. B. (2015). Inequality: What can be done? Cambridge: Harvard University Press.

De la Rica, S. (2015). Políticas activas de empleo: una panorámica. Madrid: FEDEA.

Eurofund. (2019). Labour market segmentation: Piloting new empirical and policy analyses. Luxembourg: Publications Office of the European Union. Retrieved from https://www.eurofound.europa.eu/publications/report/2019/ labour-market-segmentation-piloting-new-empirical-and-policy-analyses.

ILO (International Labour Office). (1999). Decent work: Report of the director-general. In 87th session, International Labour Conference, Geneva. Retrieved from http://www.ilo.org/public/ english/standards/relm/ilc/ilc87/rep-i.htm

Kazepov, Y., \& Barberis, E. (2013). Il welfare fragmmentato. Roma: Carocci Editore.

Open Access This chapter is licensed under the terms of the Creative Commons Attribution 4.0 International License (http://creativecommons.org/licenses/by/4.0/), which permits use, sharing, adaptation, distribution and reproduction in any medium or format, as long as you give appropriate credit to the original author(s) and the source, provide a link to the Creative Commons licence and indicate if changes were made.

The images or other third party material in this chapter are included in the chapter's Creative Commons licence, unless indicated otherwise in a credit line to the material. If material is not included in the chapter's Creative Commons licence and your intended use is not permitted by statutory regulation or exceeds the permitted use, you will need to obtain permission directly from the copyright holder.

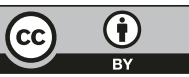

